\title{
Postoperative wound infections following myocutaneous flap surgery in spinal injury patients
}

\author{
M Garg MD, ${ }^{1}$ S Rubayi MD FICS, ${ }^{2}$ J Z Montgomerie MB ChB FRACP ${ }^{3}$ \\ ${ }^{1}$ Fellow, Infectious Disease Division, Department of Medicine, Rancho Los Amigos \\ Medical Center, Downey, California 90242, USA; ${ }^{2}$ Chief, Pressure Ulcer Management \\ Service, Department of Surgery, Rancho Los Amigos Medical Center, Downey, \\ California 90242, USA; ${ }^{3}$ Professor of Medicine, University of Southern California School \\ of Medicine, Los Angeles, California 90033 and Chief, Infectious Disease Division, \\ Department of Medicine, Rancho Los Amigos Medical Center, Downey, California \\ 90242, USA.
}

Severe pressure ulcers in patients with spinal cord injury are frequently treated by using musculocutaneous $(\mathrm{m}-\mathrm{c})$ flap surgery. There have been few studies of the use of perioperative antibiotics to prevent postoperative infection in this setting. We reviewed $74 \mathrm{~m}$-c flap surgeries in 53 patients (41 male and 12 female) from October 1989 for one year. The sites involved were ischial (31), sacral (24), trochanteric (18), deltoid (2), olecranon (1) and posterior thigh (1). An antibiotic was usually administered perioperatively for 5 days. Patients were followed for a median of 30 (8-96) weeks. Postoperative infections occurred at a median of $12(4-25)$ days in 6 of $74(8 \%)$ surgeries. The organisms cultured from the 6 infected wounds were: Bacteroides sp. (4), Proteus mirabilis (2), E. coli (2), MRSA (2), and others (6 - each isolated once).

These results indicate that antibiotics did not prevent postoperative infection in approximately $8 \%$ of patients undergoing $\mathrm{m}$-c surgery. The frequency of isolation of Bacteroides sp. from these infections suggests that anaerobic bacteria may persist in healing pressure ulcers and perioperative antibiotics might include coverage for anaerobic bacteria.

Keywords: myocutaneous flap; pressure ulcer; spinal injury; postoperative wound infection.

\section{Introduction}

Pressure ulcers are a common clinical problem in medical practice, especially among geriatric long term care, orthopedic and spinal cord injury patients. If local wound care measures fail, musculocutaneous (m-c) flap surgery is often necessary.

Antibiotic use in the perioperative period has been shown to reduce the incidence of postoperative infection after many types of surgery. Usually a first generation cephalosporin has been used and advocated, both to prevent infection from Staphylococcus found on the skin, and because of its lower cost.

There is little in the literature to guide perioperative antibiotic selection in $\mathrm{m}$-c flap surgeries. This report describes our experi- ence with m-c flap surgery in patients with spinal cord injury.

\section{Methods}

The Pressure Ulcer Management Service (PUMS) has assessed and treated both inpatients and outpatients with pressure ulcers. Those that have not responded to local wound care measures have been admitted to the hospital for more intensive care. On admission to the hospital, pressure ulcers have been graded ${ }^{1}$ and aerobic cultures obtained. Intensive hospital treatment of pressure ulcers has included appropriate ulcer debridement, dressing changes (usually normal saline, Silvadene cream and/or Dakins solution), bed rest in Clini- 
tron beds, nutritional supplements, antispasmodics and antibiotics if infection was present. Most of the ulcer debridement occurred at the bedside. Extensive ulceration and necrosis required debridement in the operating room. After the ulcer(s) were clean and granulating, the ulcer(s) (grade 3 or 4) were closed with a myocutaneous flap. Perioperative antibiotics were given usually for a period of 5 days. The surgical technique, postoperative care and rehabilitation have been described previously. ${ }^{1}$

Records of all patients with spinal cord injury seen by the Pressure Ulcer Management Service at the Rancho Los Amigos Medical Center who underwent $\mathrm{m}$-c flap surgery for pressure ulcers between October 1, 1989 and September 31, 1990 were reviewed. Patients were excluded if spinal cord injury was non traumatic (ie spina bifida, transverse myelitis, multiple sclerosis) in origin. Fifty-three patients were identified.

The criteria for identifying patients with postoperative wound infection included one or more of the following: (a) gross pus from the wound; (b) wound drainage that was culture positive; (c) infected hematoma; (d) cellulitis; (e) wound dehiscence associated with a fever (temperature $\geqslant 38^{\circ} \mathrm{C}$ ) and a positive wound culture.

Heterotopic ossification was noted by its presence on plain $\mathrm{x}$-ray, bone scan and/or biopsy.

\section{Statistical methods}

Differences in observed frequencies between infected and noninfected groups were estimated by calculation of $p$ values from chi-square using $2 \times 2$ contingency tables.

Means and standard deviations were analyzed statistically using the Student $t$-test, and $p$ estimated from a standard $t$-table.

\section{Results}

The clinical features of the 53 patients who underwent $\mathrm{m}-\mathrm{c}$ flap surgery are shown in Table I. The median age of the patients was 35 years; males predominated 3:1. Fifteen patients $(28 \%)$ had had prior flap surgery. Contractures at any site were noted in $9 \%$ of patients. Spasms, generally in the lower extremities, were present in 22 patients $(42 \%)$. A median of 10 days elapsed between hospital admission and the first flap surgery in these patients.

Eleven patients $(21 \%)$ had associated medical problems that included diabetes, alcoholism and drug abuse. Only one of the 5 diabetic patients developed an infected flap. There were no significant statistical differences (age, etc) between the clinical

Table I Patients

\begin{tabular}{lc}
\hline Number of patients & 53 \\
Age (years) [median and range] & $35[16-81]$ \\
Males & $41(77 \%)$ \\
Cervical injury & $15(28 \%)$ \\
Years injured [median and range] & $6[3$ weeks-39 years] \\
Prior flap surgery & $15(28 \%)$ \\
Ulcer onset (months) [median and range] & $6.5[0.5-78]$ \\
Contractures & $5(9 \%)$ \\
Spasms & $22(42 \%)$ \\
Infected hips & $7(13 \%)$ \\
Associated diseases: & \\
None & $42(79 \%)$ \\
Diabetes & 5 \\
Drug abuse & 5 \\
Alcoholism & 3 \\
Cancer (laryngeal) & 1 \\
Days from admission to first flap surgery [median and range] & $10[1-134$ days] \\
\hline
\end{tabular}


features of the infected and noninfected patient groups.

Patients often presented with multiple pressure ulcers requiring $\mathrm{m}$-c flap surgery. The sites of ulceration in the patients are given in Table II.

At the time of admission to the hospital the pressure ulcers were $5.1 \pm 2.8 \mathrm{~cm}$ (mean $\pm \mathrm{SD})$ in diameter $(\mathrm{n}=75)$ with $2.4 \pm 2.6 \mathrm{~cm}$ undermining $(\mathrm{n}=67)$. Underlying bone was visible in $66 \%$ (49 of 74 ) of the ulcers, $60 \%$ (44 of 73 ) were granulating, $40 \%$ (29 of 73 ) were necrotic, $15 \%$ (11 of 72) were purulent and cellulitis was present in $7 \%$ (5 of 70$)$. Underlying heterotopic ossification was identified in $31 \%$ (22 of 73 ) of pressure ulcers.

Prior to flap surgery, the pressure ulcers were managed with a range of different dressings (see Methods). Local debridement was recorded in $67 \%$ (50 of 75 ) of ulcers. Seven patients were taken to the operating room for debridement prior to $\mathrm{m}$-c flap surgery. Operating room debridement in the infected group ( 3 of 6 ) was statistically greater than in the noninfected group (4 of 68) $(p=.005)$. Descriptions of the pressure ulcers on admission and the preoperative wound care did not differ statistically between patients with and without postoperative wound infections.

Seventy-four m-c flap surgeries were done to close the 77 pressure ulcers (Table III).
The discrepancy between the number of pressure ulcers and flap surgeries is accounted for as follows: 2 patients had bilateral ischial pressure ulcers (4 ulcers) and both underwent a total thigh flap (2 surgeries), and one patient in the noninfected group had an ischial and sacral pressure ulcer ( 2 ulcers) that was closed by a single gluteus maximus flap.

The antibiotic(s) used perioperatively are shown in Table IV. All patients except 2 received a dose of antibiotic(s) prior to the initial surgical incision. These 2 patients had 3 flaps which did not become infected. In instances where the antibiotic(s) given preincision differed from those given postoperatively, the perioperative antibiotics listed in Table IV include all antibiotics given.

Vancomycin was used in a total of $15 \mathrm{~m}-\mathrm{c}$ flap surgeries, in 12 of which MRSA had been isolated preoperatively from the patients' pressure ulcers and in 3 of which MRSA had been isolated elsewhere. Analysis of perioperative antibiotic use did not reveal that any antibiotic (or combination of antibiotics) was statistically superior to others in preventing infection.

The duration of perioperative antibiotics was not significantly different between the flaps that became infected and those that did not.

Ceftazidime (alone or in combination

Table II Sites of ulcers

\begin{tabular}{lcc}
\hline Sites of ulcers & No. sites (53 patients) & $\begin{array}{c}\text { Postoperative infections } \\
\text { (6 patients) }\end{array}$ \\
\hline Ischial & 31 & $3^{* *}$ \\
Trochanter & 18 & 3 \\
Sacral & 24 & \\
Deltoid & 2 & 7 \\
Olecranon & 1 & 1 \\
Posterior thigh & 1 & 7 \\
Total number of ulcers & 77 & \\
\hline
\end{tabular}

*Sixteen patients had more than a single pressure ulcer brought to the same or different flap surgery as follows: 10 patients had 2 pressure ulcers, 4 patients had 3 pressure ulcers, and 2 patients had 4 pressure ulcers. The remaining 37 patients had a single pressure ulcer ** One patient had bilateral ischial ulcers that were covered by a single total thigh flap that became infected in the perianal area 
Table III Musculocutaneous flap surgeries

\begin{tabular}{lcc}
\hline Flap & All flaps (53 patients) & Infected flaps (6 patients) \\
\hline GMF only & 38 & 4 \\
$\quad+$ gracilis & 4 & \\
$\quad+$ gracilis/V-Y hamstring & 1 & \\
$\quad+$ V-Y hamstring/TFL & 1 & \\
$\quad+$ Vastus lateralis & 1 & \\
Bilateral GMF & 2 & \\
Split GMF & 2 & \\
TFL & 10 & \\
Vastus lateralis & 5 & \\
V-Y hamstring & 5 & \\
Deltoid & 2 & \\
Total thigh & 2 & \\
Olecranon & 1 & \\
Total flaps done & 74 & \\
\hline
\end{tabular}

GMF $=$ Gluteus maximus flap

$\mathrm{TFL}=$ Tensor fascia lata

Table IV Perioperative antibiotics administered for flap surgeries

\begin{tabular}{|c|c|c|}
\hline Antibiotic(s) & Noninfected flaps & Infected flaps \\
\hline Ceftazidime alone & 27 & 3 \\
\hline + vancomycin & 6 & 2 \\
\hline+ ampicillin/sulbactam & 13 & \\
\hline + ampicillin & 1 & \\
\hline + ampicillin/clindamycin & 1 & \\
\hline Ceftazidime/vancomycin/ampicillin/sulbactam & 2 & \\
\hline Ampicillin/sulbactam & 11 & 1 \\
\hline + vancomycin & 5 & \\
\hline Imipenem & 2 & \\
\hline Total courses of perioperative antibiotics: & 68 & 6 \\
\hline Duration of antibiotics postoperatively (days) & $* 6.3 \pm 4.0$ & $6.7 \pm 2.1$ \\
\hline Duration of surgery (minutes) & $* 208.5 \pm 63.1(57)$ & $276.7 \pm 101.4(6) p<.025$ \\
\hline Duration of surgery/flap (minutes) & $* 166.5 \pm 61.0(68)$ & $225.4 \pm 110.7(6) p<.05$ \\
\hline
\end{tabular}

${ }^{*}$ Mean \pm Standard Deviations

with other antibiotics) given perioperatively failed to prevent infection in a total of 5 cases, and ampicillin/sulbactam failed in one case.

The mean duration of surgery, and the mean duration of surgery per flap were both statistically longer in the infected group.

The nature of the wound and the bacteria subsequently cultured from the infected flaps postoperatively is shown in Table $\mathrm{V}$. Four of the 6 patients had purulent drain- age, one patient had an infected hematoma and one patient had flap dehiscence without purulent drainage. Although this patient (Patient 2) was afebrile and without leucocytosis, the wound of this patient was described as 'dirty' and the patient received 5 days of ceftazidime.

Cultures of the wounds from 2 patients (Patients 1 and 4) grew out a total of 3 different species of Bacteroides. Neither patient had received perioperative an- 
Table V Infected flap surgeries

\begin{tabular}{|c|c|c|c|c|c|}
\hline Patient & $\begin{array}{l}\text { Perioperative } \\
\text { antibiotic(s) }\end{array}$ & Infection criteria & Bone culture & $\begin{array}{l}\text { Culture of } \\
\text { drainage/pus/ } \\
\text { hematoma }\end{array}$ & $\begin{array}{l}\text { Antibiotic } \\
\text { treatment }\end{array}$ \\
\hline 1 & ceftazidime & $\begin{array}{l}\text { infected hema- } \\
\text { toma drainage }\end{array}$ & $\begin{array}{l}\text { Enterococcus sp. } \\
\text { E. cloacae } \\
\text { B. theta } \\
P . \text { aeruginosa }\end{array}$ & $\begin{array}{l}\text { B. caccae } \\
\text { B. theta }\end{array}$ & $\begin{array}{l}\text { ampicillin } \\
\text { ceftazidime } \\
\text { clindamycin } \\
*\end{array}$ \\
\hline 2 & ceftazidime & $\begin{array}{l}\text { flap dehiscence } \\
\text { appearance of } \\
\text { wound }\end{array}$ & Enterococcus sp. & no report & $\underset{*}{\text { ceftazidime }}$ \\
\hline $3^{\mathrm{a}}$ & ceftazidime & $\begin{array}{l}\text { fever } \\
\text { purulent drainage } \\
\text { flap dehiscence }\end{array}$ & not done & $\begin{array}{l}\text { MRSA } \\
\text { Enterococcus sp. } \\
\text { nonent Grp. D } \\
\text { strep } \\
\text { S. epidermis } \\
\text { Candida albicans }\end{array}$ & $\begin{array}{l}\text { ampicillin } \\
\text { ceftazidime } \\
\text { vancomycin } \\
*\end{array}$ \\
\hline 4 & $\begin{array}{l}\text { vancomycin/ } \\
\text { ceftazidime }\end{array}$ & $\begin{array}{l}\text { fever } \\
\text { purulent drainage }\end{array}$ & $\begin{array}{l}\text { Staphylococcus } \\
\text { (coag negative) }\end{array}$ & $\begin{array}{l}\text { E. coli } \\
\text { P. mirabilis } \\
\text { B. fragilis }\end{array}$ & $\begin{array}{l}\text { ceftazidime/ } \\
\text { metronidazole }\end{array}$ \\
\hline $5^{\mathrm{a}}$ & $\begin{array}{l}\text { vancomycin/ } \\
\text { ceftazidime }\end{array}$ & $\begin{array}{l}\text { purulent drainage } \\
\text { flap dehiscence }\end{array}$ & not done & $\begin{array}{l}\text { MRSA } \\
P . \text { mirabilis } \\
\text { diphtheroids }\end{array}$ & none \\
\hline 6 & $\begin{array}{l}\text { ampicillin/ } \\
\text { sulbactam }\end{array}$ & purulent drainage & S. epidermidis & $\begin{array}{l}\text { E. coli } \\
\text { Morganella sp. } \\
\text { B. fragilis }\end{array}$ & $\underset{*}{\text { ciprofloxacin }}$ \\
\hline
\end{tabular}

* = required surgical revision

a $=$ Postoperative infection of the flap in patients 3 and 5 developed only after repair of dehiscence of the wound on days 28 and 49 respectively after the initial flap surgery

aerobic antibiotic coverage. Cultures from another patient (Patient 6) who had received perioperative coverage with ampicillin/sulbactam also grew out Bacteroides. The E. coli and Morganella sp. isolated concurrently were resistant to ampicillin/ sulbactam.

MRSA was isolated in 2 patients (Patients 3 and 5) only one of whom was known to be colonized with MRSA (Patient 5). The isolation of MRSA in infected flaps (2 of 5 culture positive cases) occurred with no greater frequency than preoperative isolation of MRSA in subsequently noninfected flaps (11 of 68 flaps) ( $p=0.46)$.

Bone biopsies had been obtained at the time of flap surgery from 4 of the 6 patients with postoperative infections. There was no correlation between bone cultures at the time of flap surgery and cultures from infected drainage except in Patient 1 who had $B$. thetaiotaomicron isolated from both bone and drainage.

Changes consistent with chronic osteomyelitis were present on biopsy of bone underlying a pressure ulcer in one of 4 patients in the infected group (Patient 6). The incidence of these changes was not significantly different from the incidence in the noninfected group (28 of 55 cases) $(p=0.63)$.

Four of the 6 patients with infected flaps required subsequent surgical operating room revisions.

Two of the 6 infections occurred in surgical revisions of dehisced $\mathrm{m}$-c flaps done on the same hospital admission.

\section{Discussion}

We found postoperative m-c flap infection occurred in 6 of 74 flap surgeries $(8 \%)$. In 
the only study we were able to find specifically addressing myocutaneous flap infections, Salzberg et $a l^{2}$ reported only one postoperative infection in 40 flap surgeries $(2.5 \%)$ where 7 days of perioperative antibiotics were used. No infections occurred in 35 subsequent pressure ulcers repaired by $\mathrm{m}$-c flaps that were given 7 perioperative days of a third generation cephalosporin. The criteria for infection, patient characteristics, sites and severity of pressure ulcerations, and other variables, however, were not described, making a comparison with our study difficult.

In a previous study from our institution, Sapico et $\mathrm{al}^{3}$ described microbial colonization of pressure ulcers in various stages of healing. Anaerobic microorganisms that colonized necrotic pressure ulcers were not present in the same ulcers in the healing stages. Since the pressure ulcers of the patients in the present study were granulating and without necrosis at the time of surgery, subsequent infection of flap wounds with anaerobes in 3 of 6 cases was therefore not anticipated. A range of gram negative aerobic bacilli (E. coli, $P$. mirabilis, and Morganella sp.) were also isolated from these wounds. MRSA was cultured from the postoperative flap wounds of 2 patients. We are unaware of other reports of the bacteriology of infected flaps.

Infections of the surgical flap did not implicate infection of the underlying bone as a causative factor. Bone biopsies taken at the time of flap surgery showed histological changes consistent with chronic osteomyelitis in 29 of 59 ulcerations studied. These changes were described in only one m-c flap (Patient 6) which became infected. These results are consistent with previous observa- tions that the histopathologic changes of chronic osteomyelitis underlying pressure ulcers in spinal cord injured patients is not associated with delayed healing, flap failure or recurrence of the pressure ulcer. ${ }^{4}$

Factors associated with postoperative infection included surgical revision of a flap following dehiscence, and increased duration of operating time of flap surgery.

Surgical debridement in the operating room at some time prior to $\mathrm{m}$-c flap repair was also strongly associated with subsequent flap infection. This probably reflects the greater extent of ulceration at the time of closure because of the previous debridement of necrotic tissue.

A survey of current perioperative antibiotic use among 50 centers which routinely performed flap surgery for pressure ulcers ${ }^{2}$ underscored a lack of consensus on type, duration or even the need for perioperative antimicrobial use. Despite the lack of superior efficacy of any perioperative antibiotic(s) in the present study, good anaerobic coverage was lacking in 5 of the 6 infected flaps (and 2 of 3 infected flaps from which Bacteroides $s p$. was isolated). This together with the known frequent colonization of anaerobes of skin in the pelvic area, suggest that perioperative antibiotics for surgeries in these cases should include anaerobic coverage. Whether this would reduce the incidence of flap infection and alter the microbiology of infected flaps requires further study.

\section{Acknowledgement}

We wish to thank Jan Hamming for her assistance in the preparation of this manuscript.

\section{References}

1 Rubayi S, Cousins S, Valentine WA (1990) Myocutaneous flaps. AORN J 52(1): 40-55.

2 Salzberg CA, Gray BC, Petro JA, Salisbury RE (1990) The perioperative antimicrobial management of pressure ulcers. Decubitus 3(2): 24-26.

3 Sapico FL, Ginunas VJ, Thornhill-Joynes M, Canawati HN, Capen DA, Klein NE et al (1986) Quantitative microbiology of pressure sores in different stages of healing. Diagn Microbiol Infect Dis 5: 31-38.

4 Thornhill-Joynes M, Gonzales F, Stewart CA, Kanel GC, Lee GC, Capen DA et al (1986) Osteomyelitis associated with pressure ulcers. Arch Phys Med Rehab 67: 314-318. 